\title{
Design and Evaluation of the Customized Product Color Combination Interface Based on Scenario Experience
}

\author{
Ying-Jye Lee ${ }^{1}$, Cheih-Ying $\mathrm{Chen}^{2}$, and Fong-Gong Wu ${ }^{3}$ \\ ${ }^{1}$ Department of Cultural Business Development, \\ National Kaohsiung University of Applied Sciences, 415 Chien Kung Road, \\ Kaohsiung 807, Taiwan, R.O.C. \\ ${ }^{2}$ Department of Multimedia Design, Fortune Institute of Technology, No.1-10, \\ Nwongchang Rd., Daliao Township, Kaohsiung County 831, Taiwan, R.O.C. \\ ${ }^{3}$ Department of Industrial Design, National Cheng Kung University, 1, Ta-Hsueh Road, \\ Tainan, Taiwan 70101, R.O.C. \\ yjlee@cc.kuas.edu.tw, cychen@center.fotech.edu.tw, \\ fonggong@mail.ncku.edu.tw
}

\begin{abstract}
The customized product color interface based on scenario experience is defined as the experienced marketing model in this study. There are 48 color combinations of the spatial image resulted from four scenario styles and 12 popular sofa colors. The image compositing technique is adopted to appear the 48 color combinations of the spatial image on computer screen. This study compares the difference between the experienced marketing model and traditional marketing model by using the evaluation items of Personal Involvement Inventory. Results show that eight evaluation items including interesting, exciting, means a lot to me, appealing, fascinating, valuable, involving, and needed for the experienced marketing model are significant better than the traditional marketing model. Besides, two evaluation items including important and relevant doesn't appear significance between the two models. Therefore, the entrepreneur who wants to display the color primarily commodity should design the customized color combination interface with scenario experience for consumers to take opportunity to find the appropriate products to meet with consumers' needs, so as to shorten communication time between entrepreneurs and consumers.
\end{abstract}

Keywords: Customized product; Color combination; image compositing technique; Personal Involvement Inventory.

\section{Introduction}

In new age, the new consumption attaches great importance to consumer experience. Consumers gradually take to expend in the process that brings the unforgettable experience; and the traditional marketing have some changes. Nowadays, consumers have already regarded product function, benefit and quality as essentiality, and they need the product stimulating their perceptions and touching their thoughts. Schmitt [1] announced that the experience economy time has already approached. The experience economy for the enterprise indicates the service as the core and the product as the material to devise the sense experience, change consumer behavior, and create the feeling for the consumer which is worth recollecting [2]. 
Customization is one kind of excellent experience economy tools. Consumers can customize their own products by means of customization modules. While a product is customized, consumer goes through the active experiences at the same time. Regarding customized products, it is more easy produce to vary product's color than its form for meeting the need and preference of individual consumer. Different color combination create vary image and provide different needs for consumers [3]. Lin et al. [4] addressed the color as a key attribute in object recognition because object colors correlate strongly with object identify. Lai et al. [5] demonstrated that the product color has a greater affect on product image than product form. Wu et al. [6] noted different color products can achieve different visual effects and create more pleasing and stylish product image.

Consumers can interact with the designer or the entrepreneur by customized way. Besides, providing the diverse color component to involve the consumer in the design process, continue product life cycle, reduce product development cost and gain a higher profit [7]. Therefore, different color combinations by applying image compositing technique to the customized design interface; it will give the consumers different color fascination and design experience. However, the ordinary process of product color selection always consumed most of time in customizing and communication. The end product may fall short of consumers' expectations, since only sample pictures of the catalogue were shown to the consumers during the selection process, the finished effect of a completed product could not be effectively pictured. This vast discrepancy in the end product and consumers' expectations causes as much frustration to the consumers as well as to the manufacturers. The kind of selecting process is called the traditional model in this study.

The main objective of this study is to design the customized product design interface and to compare the difference between the experienced marketing model and traditional model. The study plans to design the customized product color interface based on scenario display via the marketing approach of experience economy. The study takes the leather sofa as an example. The sofa belongs to the large-scale commodity, and all different colors sofas can't be displayed completely in the shop. Moreover, the each different color sofa matches the different scenario to build the different spatial image for meeting consumer's need. Considering above descriptions, a customized sofa color combination interface with scenario experience is designed in this study.

\section{Image Compositing Technique}

The image compositing technique can be used in a wide variety of applications such as virtual reality which requires the scene to be displayed from different viewpoints and stereo matching [8]. Virtual environments may also be produced through the image compositing process. Definitions and descriptions in regards to virtual environments can be found in the research conducted by Bayliss et al. [9]. A good discussion on virtual reality has been presented by Machover and Tice [10] and Ellis [11]. Jayaram et al. [12] and Connacher et al. [13] also developed a virtual assembly design environment through the concept of virtual environment. From the above, it can clearly be seen that the concept of virtual environment and image compositing has already been widely adopted in many fields. This study adopts the image compositing 
technique to assist in the color combination of the sofa by letting consumers preview a virtual image of the completed work on a computer monitor. Specially, descriptions and procedures with regard to image compositing technique can be found in the research conducted by Wu et al. [14] [15].

\section{Methods}

\subsection{Scenario Style and Interface Arrangement}

In order to achieve the objective of this study, the scenario style of the study refer to the sofa style image constructed by factor analysis [16], so as to design four different scenario styles including grand, leisure, taste and vogue styles (Fig. 1) In addition, there are 12 popular sofa colors including red, orange, light yellow, yellow, light blue, blue, green, purple, black, white, brown and dark brown (see Table 1) which are suggested by five interior designers from leather samples provided by sofa industry professionals [16], and thus there are $48(4 * 12)$ color combinations of the spatial image. This study applies image compositing technique to design the customized color combination interface with scenario experience to appear 48 color combinations of the spatial image on computer screen. For example, if the scenario style is vogue and the sofa color is orange, then the customized color combination interface with scenario experience of the spatial image appears as Fig. 2.

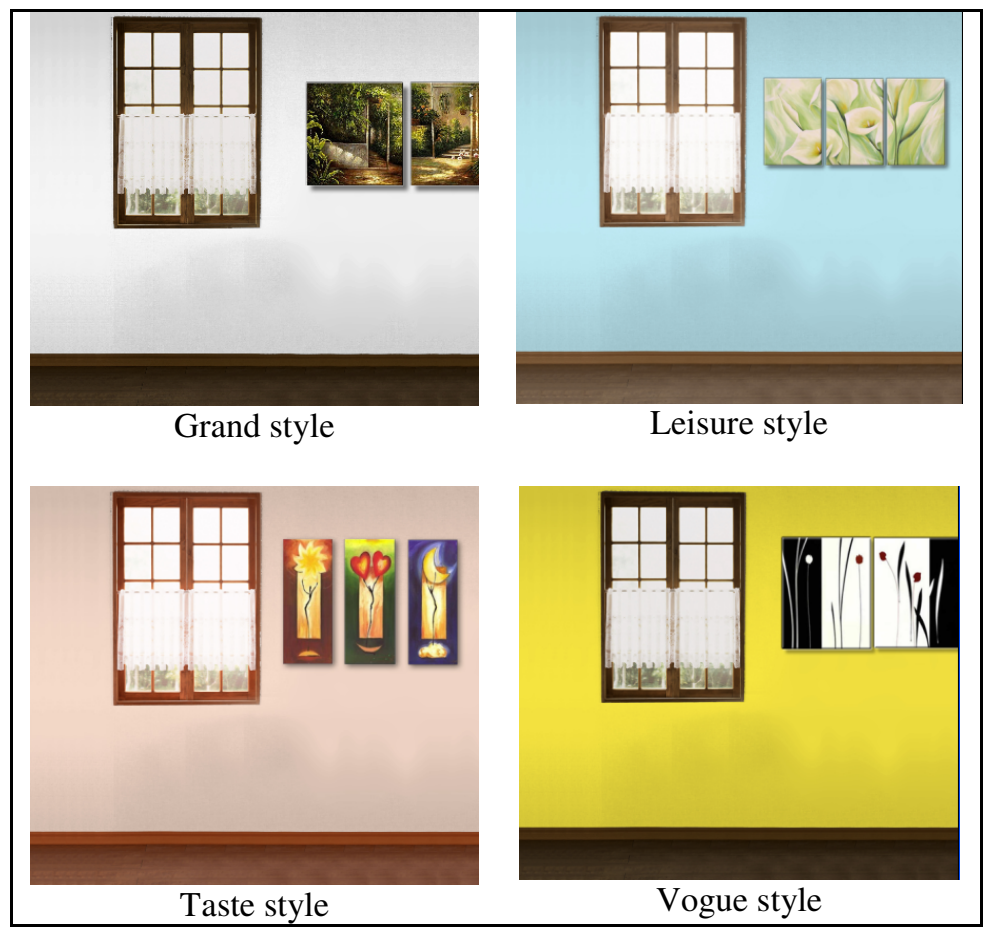

Fig. 1. The four different scenario styles in this study 
Table 1. The 12 popular sofa colors

\begin{tabular}{lll}
\hline Color name & Color Chip & Lab Color space \\
\hline White & L93, a1, b2 \\
Red & L45, a46, b18 \\
Orange & L69, a35, b54 \\
Light Yellow & L90, a-1, b41 \\
Yellow & L86, a7, b75 \\
Green & L37, a-13, b2 \\
Light Blue & L78, a-17, b0 \\
Blue & L38, a2, b-47 \\
Purple & L31, a31, b-36 \\
Light Brown & L72, a5, b29 \\
Dark Brown & L36, a7, b9 \\
Black & L40, a0, b3 \\
\hline
\end{tabular}

\section{The Customized Sofa Color Combination Interface}
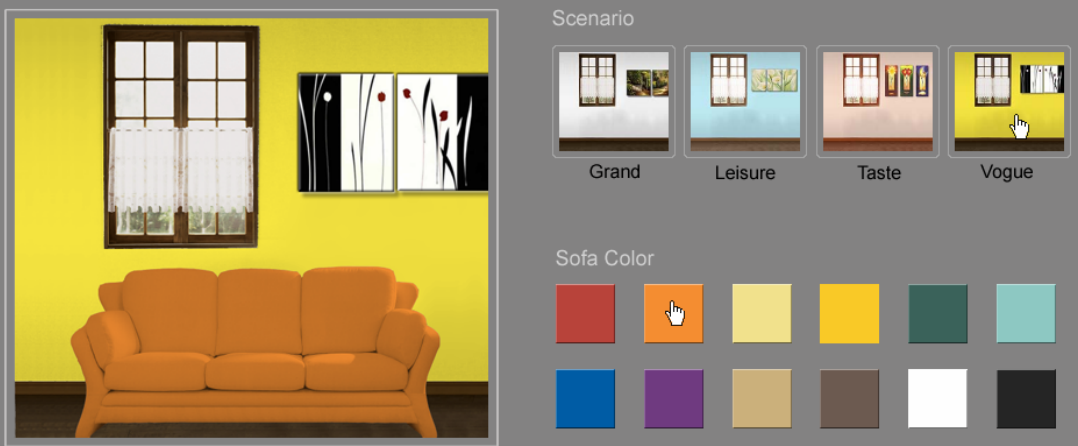

Sofa Color

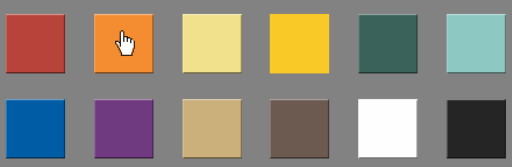

Fig. 2. The customized color combination interface with scenario experience

\subsection{Participants}

To attain effective results, this study invites 30 consumers who visit or purchase some house fitting from the furniture shop to participate in interface evaluation, 16 males and 14 females, with ages ranging from 26 to 48 (mean=35.7, SD=5.2), and all possessed a normal or after correction, eyesight of 1.0., and requests the participants to operate the customized color combination interface of the scenario experience. 


\subsection{Apparatus/Stimuli}

A multimedia computer was used here to assist in the process of interface evaluation. Additionally, a high-resolution monitor (19") with 1440 (horizontal) $\times 900$ (vertical) pixels resolution and $60 \mathrm{HZ}$ refresh rate was used to display the experiment stimuli. Stimuli used in the evaluation process were processed composite images of the customized color combination interface, each with a dimension of 1000 (horizontal) $\times 600$ (vertical) pixels, and subtended a visual angle of $47.6^{\circ} \times 29.6^{\circ}$ from a viewing distance of $40 \mathrm{~cm}$ (Fig. 3).

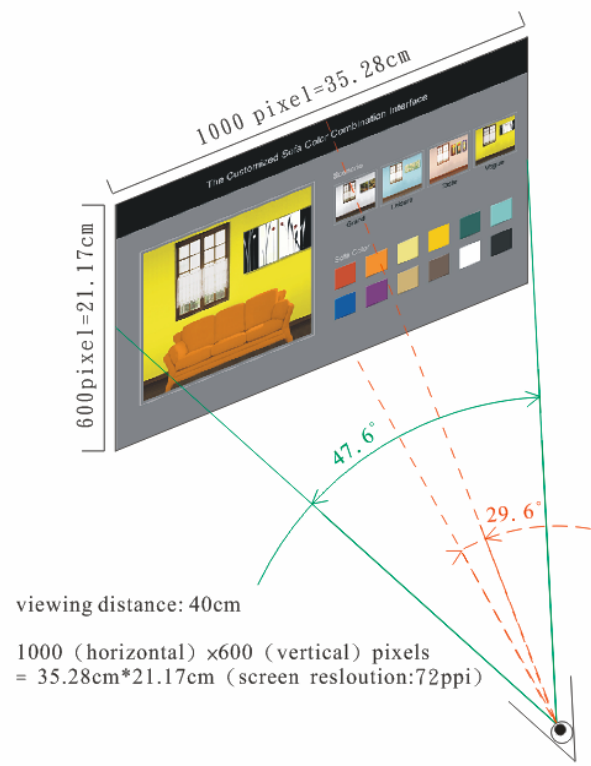

Fig. 3. The stimuli subtending a visual angle of $47.6^{\circ} \times 29.6^{\circ}$ from a viewing distance of $40 \mathrm{~cm}$

\subsection{Procedure}

Participants were seated in front of a monitor during the evaluation process. Keyboards and chairs were adjusted individually for participants to achieve a viewing distance of $40 \mathrm{~cm}$ from the screen to ensure a comfortable experimental environment. Before commencement of the interface evaluation, participants were introduced to the procedures. All the evaluating time regarding experienced marketing model for a participant is about 10 minutes. Afterwards, the study asks the participant's comments regarding the experienced marketing model (i.e. the customized color combination interface in the study) and traditional marketing model to fill in Personal Involvement Inventory [17]. Furthermore, participants were asked to make ticks on a $100 \mathrm{~mm}$ measuring scale in accordance to their evaluation of the 10 evaluation items of the PII by means of the measuring scale. Take the item "Interesting/boring" as an example (Fig. 4); the extreme left of the measuring scale corresponds to "exceedingly boring", 
and the extreme right "exceedingly interesting". After evaluation, the ticks on the degree of realistic effect marked on the measuring scale were further quantified into 0 and 10 values ( 0 representing the left side of the scale and 10 the right side). At the ending of the experiment, data collected on the reaction of participants was further statistically analyzed.

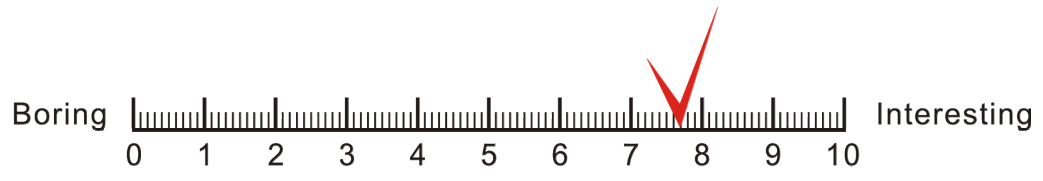

Fig. 4. The measuring scale for evaluating experienced marketing model and traditional marketing model

\section{Results and Discussion}

This study compares ten evaluation items in Personal Involvement Inventory for the experienced marketing model with traditional marketing model by T-test. Results show that the eight evaluation items including interesting, exciting, means a lot to me, appealing, fascinating, valuable, involving, and needed for the experienced marketing model are statistically significant better than the traditional marketing model (Table 2).

Table 2. T-test for comparing the experienced marketing model with traditional marketing model using the 10 evaluation items of Personal Involvement Inventory

\begin{tabular}{lccc}
\hline Evaluation item & \multicolumn{2}{c}{ Mean of Evaluation values } & $P$ value \\
\cline { 2 - 3 } & $\begin{array}{c}\text { Experienced } \\
\text { model }\end{array}$ & $\begin{array}{c}\text { Traditional } \\
\text { model }\end{array}$ & \\
\hline Important/unimportant & 6.72 & 6.99 & 0.209943 \\
Interesting/boring & 8.06 & 5.55 & $0.000000^{* *}$ \\
Relevant/irrelevant & 6.14 & 5.70 & 0.050951 \\
Exciting/unexciting & 7.90 & 6.00 & $0.000000^{* *}$ \\
means a lot to me/means nothing & 6.40 & 5.37 & $0.000498^{* *}$ \\
appealing/unappealing & 8.02 & 5.70 & $0.000000^{* *}$ \\
Fascinating/mundane & 7.90 & 5.13 & $0.000000^{* *}$ \\
valuable/worthless & 7.81 & 5.85 & $0.000000^{* *}$ \\
involving/uninvolving & 7.47 & 5.42 & $0.000000^{* *}$ \\
needed/not needed & 7.56 & 6.62 & $0.000158^{* *}$ \\
\hline
\end{tabular}

$*: \mathrm{P}<0.05 ; * *: \mathrm{P}<0.01$ 
Besides, the rest evaluation items including important and relevant doesn't appear significance between the two models. According to the analysis results, consumers have high favor on the experienced marketing model (i.e. the customized color combination interface with scenario experience). Therefore, the entrepreneur who wants to display the color primarily commodity should design the customized color combination interface with scenario experience for consumers to take opportunity to find the appropriate products to meet with consumers' needs, so as to shorten communication time between entrepreneurs and consumers.

\section{Conclusion}

The customized product color interface based on scenario experience is designed as the experienced marketing model. After evaluation, the experienced marketing model is statistically significant better than the traditional marketing model. Furthermore, the image compositing technique gives consumers the advantage of viewing the customized product color interface on a computer screen, thus enabling them to effectively select suitable spatial image that best suit their needs. The experienced marketing model based on the image compositing technique would improve on the efficiency in product color combination selection; minimize communication time between entrepreneur and consumer. The proposed experienced marketing model in this study may also be extended to similar researches in other furnishing related industries.

\section{Acknowledgments}

This research was partially supported by the National Science Council in Taiwan through Grant NSC 96-2411-H-151 -001 and NSC 97-2410-H-151-010.

\section{References}

1. Schmitt, B.H.: Experiential Marketing: How to Get Customers to Sense, Feel, Think, Act. Relate Free Press (1999)

2. Pine II, B., Joseph, Gilmore, J.H.: The Experience Economy: Work Is Theatre \& Every Business a Stage. Harvard Business School Press (1999)

3. Chronicle Books Inc., The color book (1997)

4. Lin, Z., Wang, J., Ma, K.K.: Using eigencolor normalization for illumination-invariant color object recognition. Pattern Recognition 35(11), 2629-2642 (2002)

5. Lai, H.H., Lin, Y.C., Yeh, C.H., Wei, C.H.: User-oriented design for the optimal combination on product design. International Journal of Production Economics 100(2), 253-267 (2006)

6. Wu, F.G., Chen, C.H., Lee, Y.J.: Optimum product color combination using the FAHP approach combined with the image compositing technique. In: HCI International 2005, Las Vegas, USA (2005)

7. Chen, C.Y., Lee, Y.J., Wu, F.G., Su, C.F.: Screen Layout on Color Search Task for Customized Product Color Combination Selection. In: Jacko, J.A. (ed.) HCI 2007. LNCS, vol. 4551, pp. 32-40. Springer, Heidelberg (2007) 
8. Zhang, Z.Y.: A robust technique for matching two uncalibrated images through the recovery of the unknown epipolar geometry. Artificial Intell. J. 78, 87-119 (1995)

9. Bayliss, G.M., Bowyer, A., Taylor, R.I., Willis, P.J.: Virtual manufacturing. In: Proceedings of CSG 1994: Set-Theoretic Solid Modeling Techniques and Applications, pp. 353 365 (1994)

10. Machover, C., Tice, S.E.: Virtual reality. IEEE Computer Graphics and Applications 14(1) (1994)

11. Ellis, S.R.: What are Virtual Environments? IEEE Computer Graphics and Applications 14(1) (1994)

12. Jayaram, S., Connacher, H.I., Lyons, K.W.: Virtual assembly using virtual reality techniques. Computer-Aided Design 29, 575-584 (1997)

13. Connacher, H.I., Jayaram, S., Lyons, K.: Virtual assembly design environment. In: Proceedings of 1995 Computers in Engineering Conference, Boston, MA (1995)

14. Wu, F.G., Lee, Y.J., Chen, C.H.: Evaluation of the Realistic Effect of Image Compositing to Assist in Curtain Selection. International Journal of Industrial Ergonomics 32(1), 1-12 (2003)

15. Wu, F.G., Lee, Y.J., Lin, M.C.: Using the fuzzy analytic hierarchy process on optimum spatial allocation. International Journal of Industrial Ergonomics 33(6), 553-569 (2004)

16. Ma, M.Y., Chen, C.Y., Wu, F.G.: A design decision-making support model for customized product color combination. Computers in Industry 58(6), 504-518 (2007)

17. Zaichkowsky, J.K.: Measuring the Involvement Constructure. Journal of Consumer Research 12(3), 341-352 (1985) 